\title{
The Reliability of the Tracheoesophageal Groove and the Ligament of Berry as Landmarks for Identifying the Recurrent Laryngeal Nerve: A Cadaveric Study and Meta-Analysis
}

\author{
Brandon Michael Henry, ${ }^{1,2}$ Beatrice Sanna, ${ }^{3}$ Matthew J. Graves, ${ }^{1,2}$ Silvia Sanna, \\ Jens Vikse, ${ }^{1,5}$ Iwona M. Tomaszewska, ${ }^{6}$ R. Shane Tubbs, ${ }^{7}$ and Krzysztof A. Tomaszewski ${ }^{1,2}$ \\ ${ }^{1}$ International Evidence-Based Anatomy Working Group, Krakow, Poland \\ ${ }^{2}$ Department of Anatomy, Jagiellonian University Medical College, Krakow, Poland \\ ${ }^{3}$ Faculty of Medicine and Surgery, University of Cagliari, Sardinia, Italy \\ ${ }^{4}$ Department of Surgical Sciences, University of Cagliari, Sardinia, Italy \\ ${ }^{5}$ Division of Medicine, Stavanger University Hospital, Stavanger, Norway \\ ${ }^{6}$ Department of Medical Education, Jagiellonian University Medical College, Krakow, Poland \\ ${ }^{7}$ Seattle Science Foundation, Seattle, WA, USA
}

Correspondence should be addressed to Brandon Michael Henry; bmhenry55@gmail.com

Received 14 December 2016; Revised 30 December 2016; Accepted 4 January 2017; Published 8 February 2017

Academic Editor: Roberto Cirocchi

Copyright (C) 2017 Brandon Michael Henry et al. This is an open access article distributed under the Creative Commons Attribution License, which permits unrestricted use, distribution, and reproduction in any medium, provided the original work is properly cited.

Purpose. The aim of this meta-analysis was to provide a comprehensive evidence-based assessment, supplemented by cadaveric dissections, of the value of using the Ligament of Berry and Tracheoesophageal Groove as anatomical landmarks for identifying the Recurrent Laryngeal Nerve. Methods. Seven major databases were searched to identify studies for inclusion. Eligibility was judged by two reviewers. Suitable studies were identified and extracted. MetaXL was used for analysis. All pooled prevalence rates were calculated using a random effects model. Heterogeneity among included studies was assessed using the Chi ${ }^{2}$ test and the $I^{2}$ statistic. Results. Sixteen studies ( $n=2,470$ nerves), including original cadaveric data, were analyzed for the BL/RLN relationship. The RLN was most often located superficial to the BL with a pooled prevalence estimate of $78.2 \%$ of nerves, followed by deep to the BL in $14.8 \%$. Twenty-three studies ( $n=5,970$ nerves) examined the RLN/TEG relationship. The RLN was located inside the TEG in 63.7\% (95\% CI: 55.3-77.7) of sides. Conclusions. Both the BL and TEG are landmarks that can help surgeons provide patients with complication-free procedures. Our analysis showed that the BL is a more consistent anatomical landmark than the TEG, but it is necessary to use both to prevent iatrogenic RLN injuries during thyroidectomies.

\section{Introduction}

Surgeons use various techniques to identify the Recurrent Laryngeal Nerve (RLN) during operative procedures on the neck. These range in palpation, direct inspection, intraoperative nerve monitoring, and anatomical landmarks such as the suspensory ligament of the thyroid gland (Ligament of Berry, BL) and the Tracheoesophageal Groove (TEG). The BL is a fibrous structure that anchors the thyroid gland to the first three rings of the tracheal cartilage [1, 2] (Figure 1). It can help to identify the RLN during surgical procedures, but this has yet to be widely accepted and implemented as standard practice [3]. The TEG, the sulcus formed by the abutment of the trachea anteriorly and esophagus posteriorly, is also useful for identifying the RLN [4].

The RLN is the structure most at risk for iatrogenic injury during procedures on the anterior neck, particularly thyroidectomy [5]. The most common site of injury to the RLN is near the BL, where the nerves penetrate into the larynx $[3,6]$. A reliable landmark and method for identifying the RLN is necessary to prevent postoperative complications such as hoarseness and vocal cord paralysis. The location of the RLN with respect to the BL has varied widely in previous reports, ranging from a piercing pattern in $0 \%$ of 


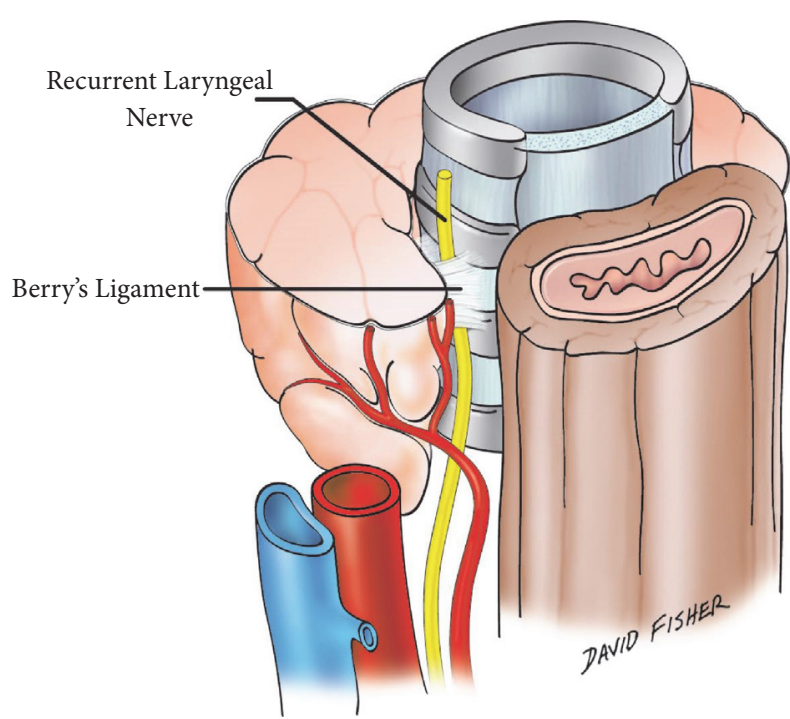

FIgURE 1: Anatomical location of the Berry Ligament.

cases in Berlin and Lahey (1929), Çakir et al. (2006), Freschi et al. (1994), Hunt et al. (1968), Leow and Webb (1998), and Sasou et al. (1998) [2, 7-11] to 31.6\% in Pradeep et al. (2012) [12]. A more complete understanding of the frequency with which nerves penetrate the $\mathrm{BL}$ will reduce complications, as traction-related injuries are associated with RLNs taking a piercing course $[6,10]$. The TEG can also be useful for identifying the RLN and offers a fairly safe haven for the RLN as it ascends towards the larynx [13]. An unaware surgeon could overlook a nerve coursing in the TEG because its course is somewhat concealed, so the TEG needs to be assessed for the presence of the RLN [13].

Reports of the location and relationship of the RLN to the BL and TEG have varied widely. The reported presence of an RLN coursing within the TEG has ranged from $24.9 \%$ to $100 \%[14,15]$. The RLN's relationship to the BL seems to be even more variable, with the nerve coursing superficially to the ligament in anywhere between $0 \%$ and $100 \%$ of cases $[2,7,8,11,16]$. The high variability of the data published to date allows no firm assessment to be made of the value of the BL or TEG as landmarks for neural identification.

The high rate of RLN injury, and the need to protect the structure during surgery, has motivated extensive research during recent years. However, a reliable and uniform method for isolating and safeguarding the nerve has yet to be formulated. Our intention is to provide a comprehensive evidence-based assessment, supplemented by our own cadaveric study, of the anatomical reliability of the BL and TEG as landmarks for identifying the RLN. Reliable landmarks would help to reduce the rate of iatrogenic injury and long term postoperative complications.

\section{Methods}

2.1. Dissection. A total of 36 formalin-fixed cadavers were dissected bilaterally at the Department of Anatomy, Jagiellonian University Medical College, Krakow, Poland, to investigate the anatomical relationship of the RLN to the BL and TEG. A midline vertical incision was made starting from the mentum and continuing inferiorly to the sternal notch. The dissection was continued through the subcutaneous adipose tissue. Subplatysmal flaps were then raised. Next, the superior and inferior attachments of the sternohyoid and sternothyroid muscles were transected and the dissection was continued until the thyroid gland was visible. All surrounding muscles and adipose and connective tissues were then carefully removed. The RLN was visualized with the aid of medial traction on the trachea. The relationship of the nerve to the BL was recorded (superficial, piercing, or deep). The nerve was then traced inferiorly to the Tracheoesophageal Groove, and the position of the RLN with respect to this groove was recorded (inside or outside: anterior, anterolateral, lateral, and posterior).

2.2. Ethics. The research protocol for this study was approved by the Jagiellonian University Medical College Ethics Committee (registry number KBET/319/B/2012). The study was performed in accordance with the ethical standards established in the 1964 Declaration of Helsinki and its later amendments.

2.3. Search Strategy. Through August 2016, the major electronic databases PubMed, China National Knowledge Infrastructure (CNKI), ScienceDirect, EMBASE, BIOSIS, SciELO, and Web of Science were searched to identify potential studies for the meta-analysis. No date limits or language restrictions were imposed. The comprehensive PubMed search strategy is presented in Supplement 1 in Supplementary Material available online at https://doi.org/10.1155/2017/4357591. The references of all studies included in the meta-analysis were also searched to identify additional potentially eligible articles. Throughout the meta-analysis, the Preferred Reporting Items for Systematic Reviews and Meta-Analyses (PRISMA) guidelines were strictly followed [17] (Supplement 2). This meta-analysis was prospectively registered in PROSPERO (CRD42015026096).

2.4. Study Selection Criteria. Studies were considered eligible for inclusion in the meta-analysis if they (1) reported clear, extractable prevalence data on either the relationship of the RLN to the BL or the relationship of the RLN to the TEG and (2) were cadaveric, intraoperative, or imaging studies. The exclusion criteria included (1) case studies, case reports, conference abstracts, and letters to the editor; (2) studies reporting incomplete data; and (3) studies of patients with trauma to the head and neck region.

Each study was independently assessed for eligibility by at least two reviewers. Any disagreements arising during this assessment were resolved by a consensus among the entire review team, after consultation with the authors of the original study, if possible. Full-text articles in languages not spoken fluently by the reviewers were translated for further eligibility assessment by medical professionals fluent in both English and the original language of the article.

2.5. Data Extraction. Data from the included studies were independently extracted by two reviewers. The extracted data 

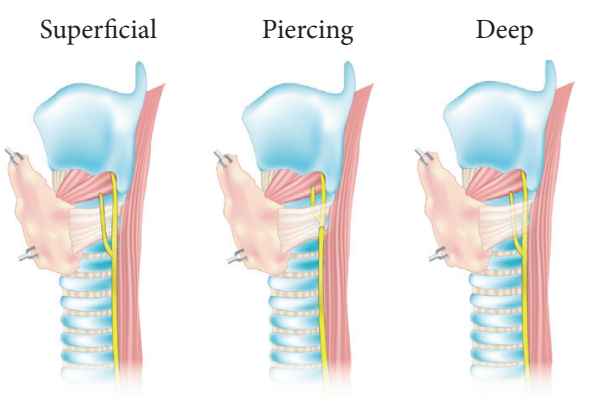

FIgURE 2: Types of relationship between the Recurrent Laryngeal Nerve and the Berry Ligament.

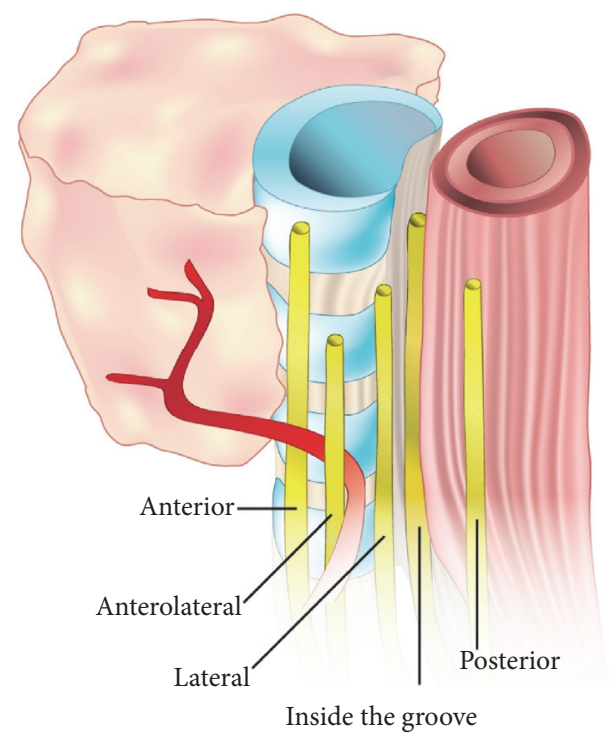

FIgURE 3: Possible locations of the Recurrent Laryngeal Nerve in relation to the Tracheoesophageal Groove.

included year, country, type of study, study design, number of nerves, prevalence of the different types of relationships of the RLN to the BL (superficial, piercing, or deep) (Figure 2), prevalence of the different types of relationship of the RLN to the TEG (inside or outside), prevalence of the different positions of the nerve when located outside the TEG with respect to the TEG (anterior, anterolateral, lateral, or posterior) (Figure 3), and symmetry in the aforementioned relationships. In the event of data discrepancies, the review team attempted to contact the authors of the original article by email for clarification.

2.6. Statistical Analysis. For the analysis of cadaveric data, prevalence rates and elements of descriptive statistics were used where appropriate. To pool the data into the metaanalysis, pooled prevalence estimates were calculated using MetaXL version 2.0 by EpiGear International Pty. Ltd. (Wilston, Queensland, Australia). A random effects model was used for all meta-analysis calculations. Heterogeneity among the included studies was measured using the $\mathrm{Chi}^{2}$ test
TABLE 1: Cadaveric data on the relationship of the Recurrent Laryngeal Nerve to the Berry Ligament.

\begin{tabular}{lccc}
\hline & Superficial: \# (\%) & Piercing: \# (\%) & Deep: \# (\%) \\
\hline Total $(n=72)$ & $65(90.3 \%)$ & $5(6.9 \%)$ & $2(2.8 \%)$ \\
Right $(n=36)$ & $33(91.7 \%)$ & $2(5.6 \%)$ & $1(2.8 \%)$ \\
Left $(n=36)$ & $32(88.9 \%)$ & $3(8.3 \%)$ & $1(2.8 \%)$ \\
\hline
\end{tabular}

and the $I^{2}$ statistic. For the Chi ${ }^{2}$ test, a Cochran's $Q p$ value of $<0.10$ indicated significant heterogeneity [18]. The results of the $I^{2}$ statistic were interpreted as follows: $0-40 \%$ might not be important; $30-60 \%$ could indicate moderate heterogeneity; $50-90 \%$ could indicate substantial heterogeneity; and 75$100 \%$ could represent considerable heterogeneity [18].

Subgroup analyses to explore potential sources of heterogeneity were based on type of study (cadaveric versus intraoperative), side (left versus right), and geographical distribution. Confidence intervals of the rates were used to investigate significant differences between subgroups, any overlap between two or more subgroups indicating a lack of statistical significance [19]. When appropriate, for studies with $\geq 100$ nerves, sources of heterogeneity were also probed by a sensitivity analysis.

\section{Results}

3.1. Cadaveric Study. Among the 36 formalin-fixed cadavers dissected, 16 (44.4\%) were men and $20(55.6 \%)$ were women. The mean age was $68.9 \pm 11.7$ years. The RLN was identified bilaterally in all 36 cadavers ( $n=72$ nerves). In 65 (90.3\%) out of the 72 nerves the RLN was located superficial to the BL (Table 1). The relationship was symmetrical in $29(80.6 \%)$ of the 36 cadavers. The RLN was located within the groove in $49(68.1 \%)$ sides and outside it in $23(31.9 \%)$. The relationship was symmetrical in $22(61.1 \%)$ of the 36 cadavers. When the RLN was located outside the groove, it was most commonly found lateral to the TEG (17 nerves, $73.9 \%$ ) (Table 2).

3.2. Study Identification. A summary of the flow of studies through the meta-analysis is presented in Figure 4. A search through the major electronic databases identified 2,795 articles, and 84 more were identified when the references of the included studies were searched. After 41 duplicates had been excluded and 2,838 records screened, 328 articles were further assessed for eligibility by full text. Among these, 295 were excluded, and 33 were included in the meta-analysis.

3.3. Meta-Analysis of the Relationship of the Recurrent Laryngeal Nerve to the Berry Ligament. A total of 16 studies $(n=$ 2,470 nerves), including the present one, were included in the analysis of the relationship of the RLN to the BL. The characteristics of the included studies are presented in Table 3. The RLN was most commonly located superficial to the BL with a pooled prevalence estimate of $78.2 \%$ (95\% CI: $51.5-90.8$ ) of nerves, followed by deep to the BL in $14.8 \%$ (95\% CI: 0-33.0), and piercing the BL in 7.0\% (95\% CI: 0-19.6) $\left(I^{2}\right.$ $=99.1 \%$; 95\% CI: 98.9-99.2; $p<0.001$ ) (Figure 5). The results 
TABLE 2: Cadaveric data on the relationship of the Recurrent Laryngeal Nerve to the Tracheoesophageal Groove.

\begin{tabular}{|c|c|c|c|c|c|c|}
\hline & $\begin{array}{c}\text { Inside TEG: \# } \\
(\%)\end{array}$ & $\begin{array}{c}\text { Outside TEG: } \\
\#(\%)\end{array}$ & $\begin{array}{l}\text { Outside- } \\
\text { anterior: \# } \\
(\%)\end{array}$ & $\begin{array}{c}\text { Outside- } \\
\text { anterolateral: } \\
\#(\%)\end{array}$ & $\begin{array}{c}\text { Outside- } \\
\text { lateral: \# (\%) }\end{array}$ & $\begin{array}{l}\text { Outside- } \\
\text { posterior: \# } \\
(\%)\end{array}$ \\
\hline Total $(n=72)$ & $49(68.1 \%)$ & $23(31.9 \%)$ & $2(8.7 \%)$ & $4(17.4 \%)$ & $17(73.9 \%)$ & $0(0.0 \%)$ \\
\hline Right $(n=36)$ & $26(72.2 \%)$ & $10(27.8 \%)$ & $2(20.0 \%)$ & $1(10.0 \%)$ & $7(70.0 \%)$ & $0(0.0 \%)$ \\
\hline Left $(n=36)$ & $23(63.9 \%)$ & $13(36.1 \%)$ & $0(0.0 \%)$ & $3(23.1 \%)$ & $10(76.9 \%)$ & $0(0.0 \%)$ \\
\hline
\end{tabular}

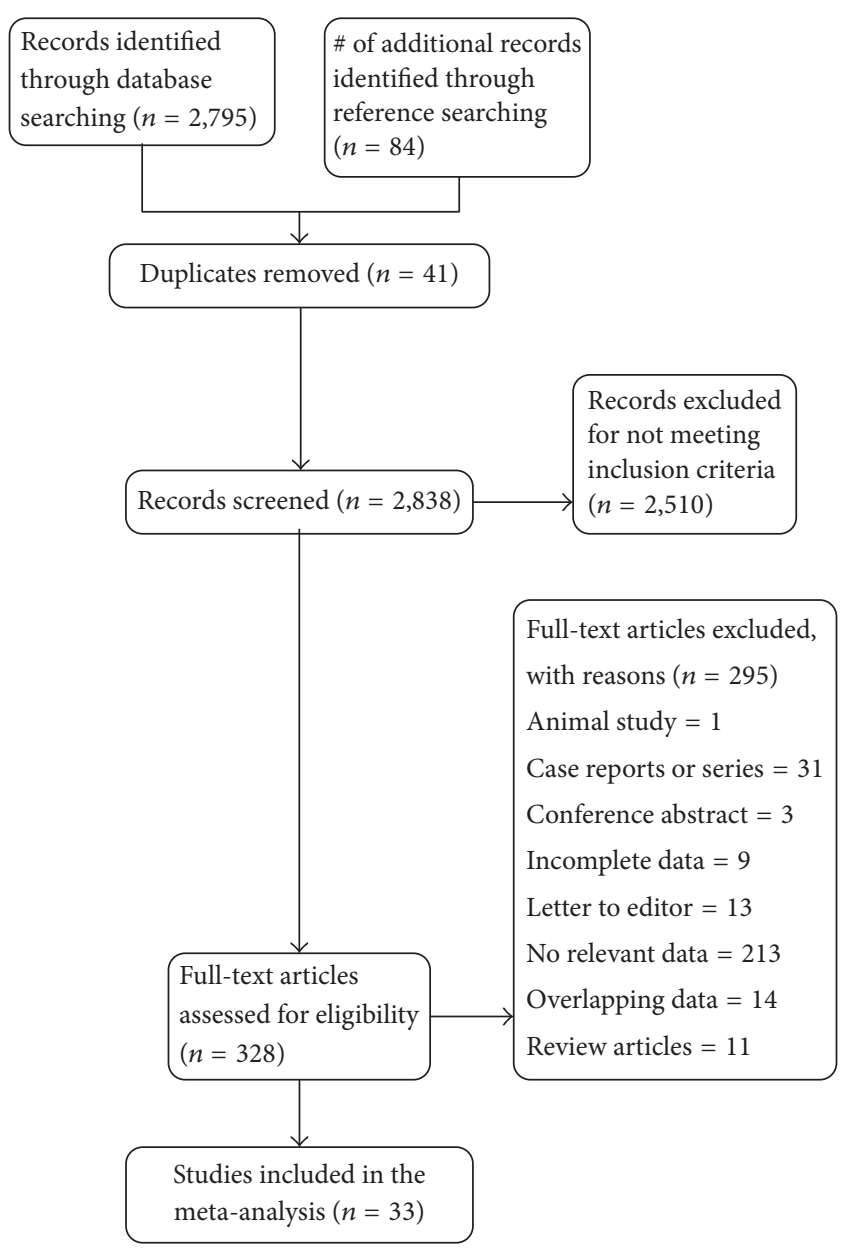

FIGURE 4: PRISMA flow chart of study identification and inclusion in the meta-analysis.

of the subgroup analyses for types and geographical origins of studies, and a sensitivity analysis, are presented in Table 4. The relationship was reported to be symmetrical in three studies ( $n=147$ subjects). It was found to be symmetrical in $75.5 \%$ (95\% CI: $64.0-85.4)$ of subjects $\left(I^{2}=47.5 \%\right.$; $95 \% \mathrm{CI}$ : $0-84.6 ; p=0.149)$.

3.4. Meta-Analysis of the Relationship of the Recurrent Laryngeal Nerve to the Tracheoesophageal Groove. A total of 23 studies ( $n=5,970$ nerves), including the present one, reported data on the relationship of the RLN to the TEG. The characteristics of the included studies are presented in Table 5. The nerve was located inside the groove in $63.7 \%$ (95\% CI:
55.3-77.7) of sides and outside it in 36.3\% (95\% CI: $28.3-44.7$ ) ( $I^{2}=97.4 \%$; 95\% CI: 96.8-97.9; $p<0.001$ ) (Figure 6). No significant differences were found in the subgroup analysis by type of study, side, or geography, or in the sensitivity analysis (Table 6$)$. In the two studies ( $n=133$ subjects) that reported symmetry data, the relationship of the RLN to the TEG was symmetrical in $44.6 \%$ (95\% CI: 15.4-75.7) of cases $\left(I^{2}=89.7 \%\right.$; 95\% CI: 62.0-97.2; $\left.p=0.002\right)$.

Ten studies ( $n=1,268$ nerves), including the present one, reported data on the position of the RLN in relation to the TEG when the nerve was located outside the groove. It was located anterior to the TEG in $45.7 \%$ (95\% CI: $1.1-$ 81.1 ) of cases and lateral to it in $37.4 \%$ (95\% CI: 0-72.1). Full 
TABLE 3: Table of studies included in the Recurrent Laryngeal Nerve-Berry Ligament meta-analysis.

\begin{tabular}{|c|c|c|c|c|c|c|}
\hline \multirow{2}{*}{ Study } & \multirow{2}{*}{ Country } & \multirow{2}{*}{ Type of study } & \multirow{2}{*}{$n=($ nerves $)$} & \multicolumn{3}{|c|}{ Berry's Ligament } \\
\hline & & & & Superficial (\%) & Piercing (\%) & Deep (\%) \\
\hline Present study & Poland & $\mathrm{C}$ & 72 & 90.3 & 6.9 & 2.8 \\
\hline Asgharpour 2012 [3] & England & $\mathrm{C}$ & 185 & 88.1 & 11.9 & 0 \\
\hline Berlin and Lahey 1929 [7] & USA & I & 44 & 100 & 0 & 0 \\
\hline Berlin 1935 [27] & USA & I & 140 & 75.0 & 25.0 & 0 \\
\hline Botelho et al. 2012 [28] & Brazil & $\mathrm{C}$ & 41 & 61.0 & 19.5 & 19.5 \\
\hline Çakir et al. 2006 [8] & Tukey & $\mathrm{C}$ & 130 & 100 & 0 & 0 \\
\hline Chen et al. 2008 [16] & China & $\mathrm{C}$ & 100 & 0 & 5 & 95 \\
\hline Freschi et al. 1994 [9] & Italy & I & 84 & 41.7 & 0 & 58.3 \\
\hline Hunt et al. 1968 [10] & Australia & $\mathrm{C}$ & 151 & 47.0 & 0 & 53.0 \\
\hline Kaisha 2011 [29] & Kenya & $\mathrm{C}$ & 121 & 67.0 & 7.4 & 25.6 \\
\hline Leow and Webb 1998 [11] & England & $\mathrm{C}$ & 25 & 100 & 0 & 0 \\
\hline Ngo Nyeki et al. 2015 [1] & Cameroon & I & 62 & 93.5 & 6.5 & 0 \\
\hline Pradeep et al. 2012 [12] & India & I & 584 & 61.8 & 31.2 & 7.0 \\
\hline Sasou et al. 1998 [2] & Japan & I & 486 & 100 & 0 & 0 \\
\hline Sunanda et al. 2010 [30] & Sri Lanka & I & 45 & 55.5 & 6.7 & 37.8 \\
\hline Wade 1955 [31] & Wales & I & 200 & 10 & 25 & 65 \\
\hline
\end{tabular}

results, along with detailed subgroup analysis by type of study, geographical origin, and side, and a subgroup analysis, are presented in Table 7.

\section{Discussion}

Anatomical landmarks such as the BL and TEG come with caveats of which surgeons need to be cognizant before using them in the operating theater.

In our cadaveric dissections, there was a $90.3 \%$ prevalence of the RLN coursing superficially to the BL. This coincides with the prevalence rates noted in studies such as those by Asgharpour et al. (2012) and Ngo Nyeki et al. (2015) [1, 3] and with the most common (78.2\%) superficial RLN/BL relationship identified in the meta-analysis. The least common type of BL relationship was the piercing pattern, with a $7.0 \%$ pooled prevalence estimate. The group with a piercing pattern, although small, needs to be diligently assessed intraoperatively owing to the risk of injuries related to glandular traction $[6,10]$. There were no statistically significant differences in subgroup analysis, but there was substantial geographical variability. Most Asian studies reported a lower prevalence of the superficial relationship (59.3\%) than their North American, African, and European counterparts, which reported pooled prevalence of $90.7 \%, 83.4 \%$, and $81.5 \%$, respectively. No differences were noted with respect to study modality (intraoperative versus cadaveric).

Symmetrical RLN patterns with respect to the BL were noted in most cases (80.6\%) in our dissections. This information is useful for surgeons performing total thyroidectomies, in that once one nerve is identified, the same location should be assessed first on the contralateral side. The RLN/BL relationship was similarly symmetrical in our meta-analysis: $75.5 \%$ of nerves behaved the same on both sides.
Our dissections revealed that the TEG is a somewhat less reliable landmark, only $68.1 \%$ of nerves coursing within the groove. This is very similar to the $63.7 \%$ pooled prevalence estimate of nerves coursing within the TEG obtained from the meta-analysis. The meta-analysis and cadaveric study differed with regard to the location of the RLN when it was outside the TEG. It was most commonly (73.9\%) located lateral to the TEG in our cadavers, but most RLNs outside the TEG (45.7\%) were found anteriorly in the meta-analysis. Differences aside, RLNs were found largely, if not exclusively, in locations ranging from anteriorly to laterally. All RLNs in our cadaveric study and $89.1 \%$ of cases in our meta-analysis lay within this range. Subgroup analysis of the RLN/TEG relationship revealed no statistically significant differences. Small differences were noted between the cadaveric (34.2\%) and intraoperative $(39.9 \%)$ accounts of those nerves found outside the TEG. We posit that pathologies resulting in these operative procedures, such as large multinodular goiters, slightly alter the physiological location of the RLN. This subanalysis revealed geographical differences, Asian studies generally reporting more RLNs coursing in the TEG $(75.9 \%)$ than European ones (50.9\%). Assessment of RLN/TEG behavior in our cadavers confirmed that the symmetrical pattern of the course (61.1\%) was slightly less common than the symmetrical behavior of the RLN with respect to the BL.

The BL has been considered one of the most reliable landmarks in neck surgery [3]. All indications from our data support that claim. The BL should be used in all cases where the RLN needs to be identified. That being said, no structure should be dissected or ligated until the RLN has been identified, because RLN injury is the most common surgical complication of the neck $[5,20]$. It is also important that surgeons consider the less common pattern of the RLN piercing the BL. These cases, in which the nerve can be 

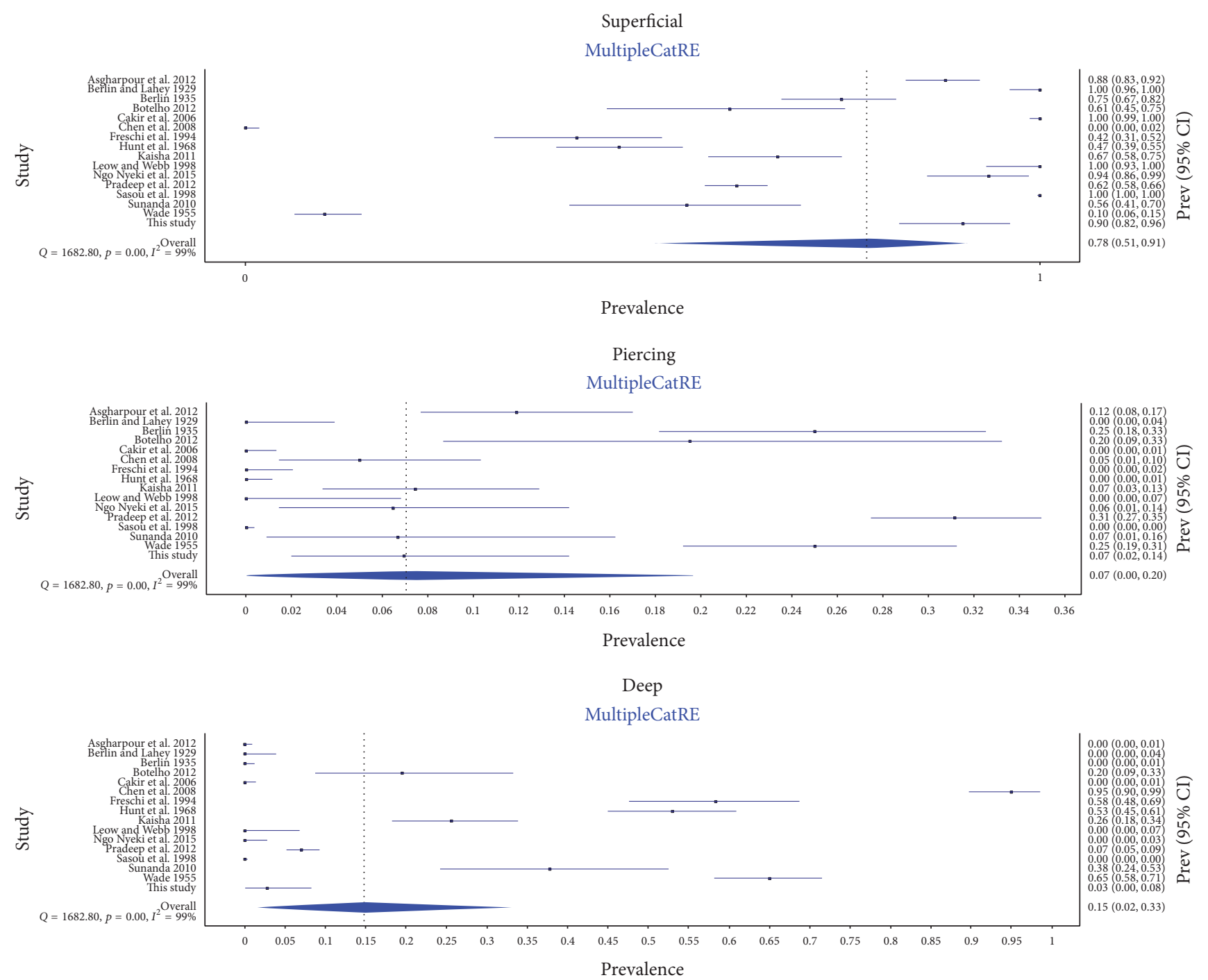

FIGURE 5: Forest plots for prevalence of Recurrent Laryngeal Nerve relationship pattern with respect to the Berry Ligament.

intricately intertwined with the $\mathrm{BL}$, pose a unique hazard in that fibers can easily be severed when the ligament is incised during thyroidectomy [21]. Instances of the RLN piercing the $\mathrm{BL}$ are associated with the highest morbidity of nerve palsy [21]. It was highlighted by Serpell in 2010 that the great variability in the relationship of the nerve to the $\mathrm{BL}$ could arise from a lack of proper anatomical assessment of the ligament itself [22]. Serpell notes that the BL comprises two fascial layers, and the RLN can be found in the deeper fibrous layer, the "true" BL [22]. This can lead to false reporting of the penetrating pattern of the $\mathrm{BL}$, which has not been directly clarified in studies reporting these variants. Furthermore, Serpell notes that a meticulous dissection of the RLN posterolaterally helps to reduce nerve traction, allowing for safe BL division and reduction in nerve palsies [22].

The TEG is a valuable landmark for identifying the RLN. It provides some shelter, inside which the nerve can be overlooked, but simple palpation of it can provide valuable information about the presence of the RLN [13]. It has also proved useful in laparoscopic procedures of the neck requiring the RLN to be identified [23]. In a series by Chang, the RLN was identified in $100 \%$ of laparoscopic thyroid procedures using the TEG [23]. We suggest that an attempt should first be made to identify the RLN in the TEG, and then the course of the nerve should be traced upwards to the $\mathrm{BL}$ to confirm the position and structure. This identification can be complicated if there are pathologies, or anatomical variations such as extralaryngeal branching of the RLN. It has been noted that $76.6 \%$ of nerves branch prior to entering the larynx [24]. Intraoperative nerve monitoring (IONM) has become more regularly used in recent years although it has yet to be proven superior to concrete anatomical landmarks $[5,25]$. That being said, IONM can be beneficial in cases where pathology does not permit these at-risk structures to be adequately visualized and identified. IONM can aid in instances where reoperation is required. It has been noted that transient postoperative complications more than quadruple according to some statistics [26]. The use of the 

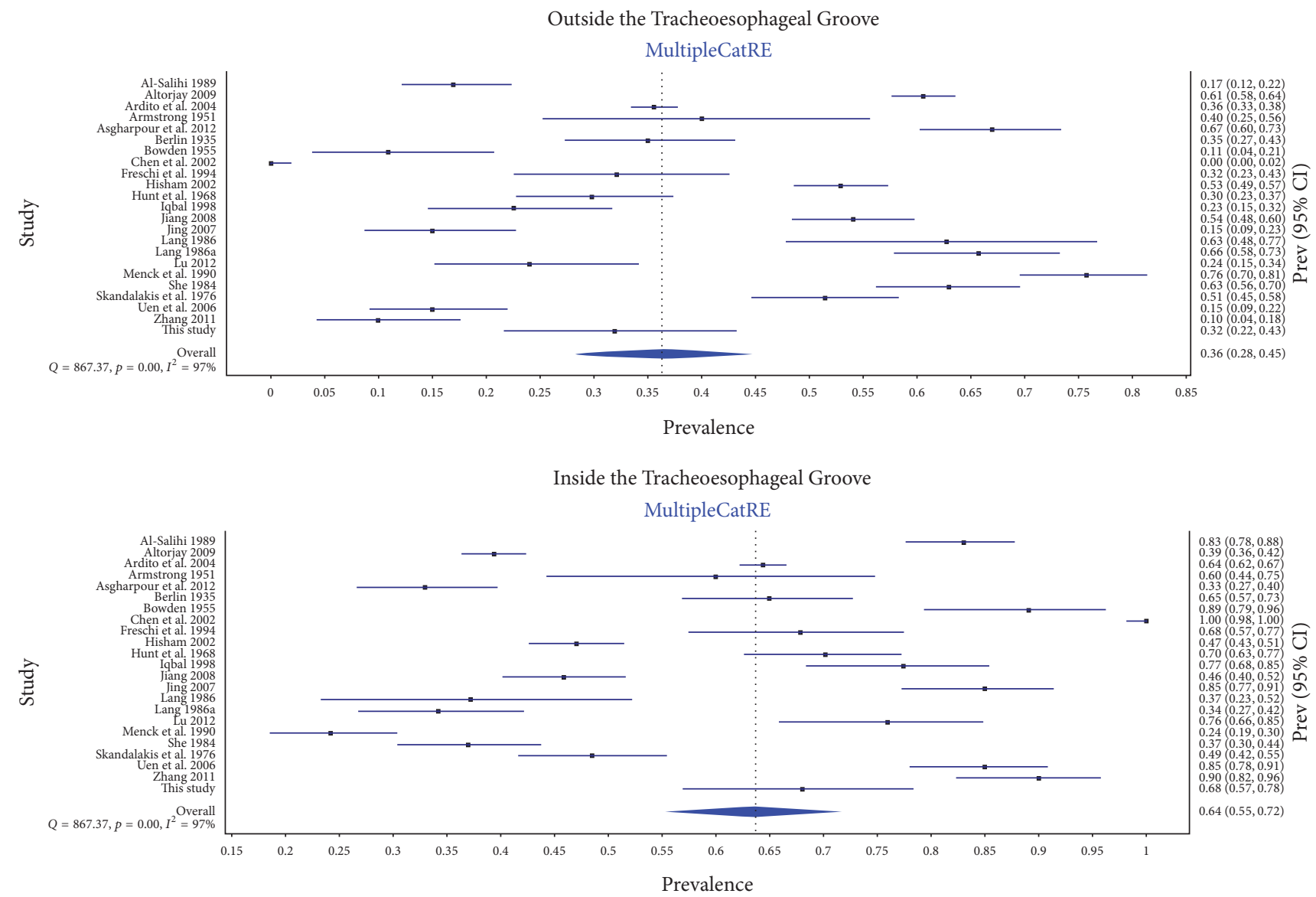

FigURE 6: Forest plots for the pooled prevalence of the Recurrent Laryngeal Nerve location with respect to the Tracheoesophageal Groove.

TABLE 4: Subgroup analysis for relationship of the Recurrent Laryngeal Nerve to the Berry Ligament.

\begin{tabular}{|c|c|c|c|c|c|}
\hline & $\begin{array}{l}\text { Number of studies } \\
\text { (number of nerves) }\end{array}$ & $\begin{array}{l}\text { Superficial: \% } \\
(95 \% \text { CI })\end{array}$ & $\begin{array}{l}\text { Piercing: \% } \\
\text { (95\% CI) }\end{array}$ & $\begin{array}{l}\text { Deep: \% } \\
(95 \% \mathrm{CI})\end{array}$ & $\begin{array}{c}I^{2}: \%(95 \% \\
C I)^{*}\end{array}$ \\
\hline Overall & $16(2470)$ & $\begin{array}{c}78.2 \\
(51.5-90.8)\end{array}$ & $7.0(0-19.6)$ & $14.8(0-33.0)$ & $\begin{array}{c}99.1 \\
(98.9-99.2)\end{array}$ \\
\hline Cadaveric & $9(965)$ & $\begin{array}{c}77.6 \\
(42.0-97.3)\end{array}$ & $6.8(0-26.5)$ & $15.5(0-40.7)$ & $\begin{array}{c}98.8 \\
(98.5-99.1)\end{array}$ \\
\hline Intraoperative & 7 (1505) & $\begin{array}{c}76.0 \\
(34.9-100)\end{array}$ & $7.0(0-32.3)$ & $17.0(0-49.4)$ & $\begin{array}{c}99.4 \\
(99.2-99.5)\end{array}$ \\
\hline Africa & $2(183)$ & $\begin{array}{c}83.4 \\
(35.9-100)\end{array}$ & $7.6(0-44.2)$ & $8.9(0-47.0)$ & $\begin{array}{c}97.2 \\
(93.0-98.9)\end{array}$ \\
\hline Asia & $4(1215)$ & $59.8(0-100)$ & $8.4(0-56.6)$ & $31.8(0-89.5)$ & $\begin{array}{c}99.6 \\
(99.5-99.7)\end{array}$ \\
\hline Europe & $6(696)$ & $\begin{array}{c}81.5 \\
(35.0-100)\end{array}$ & $5.3(0-34.3)$ & $13.2(0-50.1)$ & $\begin{array}{c}99.1 \\
(98.9-99.3)\end{array}$ \\
\hline North America & $2(184)$ & $\begin{array}{c}90.7 \\
(54.6-100)\end{array}$ & $9.0(0-45.4)$ & $0.3(0-18.1)$ & $\begin{array}{c}96.3 \\
(89.9-98.6)\end{array}$ \\
\hline $\begin{array}{l}\text { Sensitivity ( } \geq 100 \\
\text { nerves) }\end{array}$ & 9 (2097) & $\begin{array}{c}70.7 \\
(32.1-92.4)\end{array}$ & $9.0(0-30.1)$ & $20.3(0-46.7)$ & $\begin{array}{c}99.4 \\
(99.3-99.5)\end{array}$ \\
\hline
\end{tabular}

${ }^{*}$ The $p$ value of Cochran's $Q$ for all analysis was $<0.001$. 
TABLE 5: Table of studies included in the Recurrent Laryngeal Nerve-Tracheoesophageal Groove meta-analysis.

\begin{tabular}{|c|c|c|c|c|c|}
\hline \multirow{2}{*}{ Study } & \multirow{2}{*}{ Country } & \multirow{2}{*}{ Type of study } & \multirow{2}{*}{$n=($ nerves $)$} & \multicolumn{2}{|c|}{ Tracheoesophageal groove } \\
\hline & & & & Inside (\%) & Outside (\%) \\
\hline Present study & Poland & $\mathrm{C}$ & 72 & 68.1 & 31.9 \\
\hline Al-Salihi and Dabbagh 1989 [32] & Iraq & $\mathrm{C}$ & 212 & 83.0 & 17.0 \\
\hline Altorjay et al. 2009 [33] & Hungary & $\mathrm{I}$ & 1023 & 39.4 & 60.6 \\
\hline Ardito et al. 2004 [6] & England & $\mathrm{I}$ & 1856 & 64.4 & 35.6 \\
\hline Armstrong and Hinton 1951 [34] & USA & $\mathrm{C}$ & 40 & 60.0 & 40.0 \\
\hline Asgharpour et al. $2012[3]$ & England & $\mathrm{C}$ & 197 & 33.0 & 67.0 \\
\hline Berlin 1935 [27] & USA & I & 140 & 65.0 & 35.0 \\
\hline Bowden 1955 [35] & England & $\mathrm{C}$ & 55 & 89.1 & 10.9 \\
\hline Chen et al. 2002 [15] & China & $\mathrm{C}$ & 90 & 100 & 0 \\
\hline Freschi et al. 1994 [9] & Italy & I & 84 & 67.9 & 32.1 \\
\hline Hisham and Lukman 2002 [36] & Malaysia & I & 491 & 47.0 & 53.0 \\
\hline Hunt et al. $1968[10]$ & Australia & $\mathrm{C}$ & 151 & 70.2 & 29.8 \\
\hline Iqbal and Zubair 1998 [37] & Pakistan & I & 93 & 77.4 & 22.6 \\
\hline Jiang et al. 2008 [38] & China & I & 292 & 45.9 & 54.1 \\
\hline Jing et al. 2007 [39] & China & $\mathrm{C}$ & 100 & 85 & 15 \\
\hline Lang et al. 1986 [40] & Germany & $\mathrm{C}$ & 43 & 37.2 & 62.8 \\
\hline Lang et al. 1986 [41] & Germany & $\mathrm{C}$ & 146 & 34.2 & 65.8 \\
\hline Lu et al. 2012 [42] & China & I & 79 & 76.0 & 24.0 \\
\hline Menck et al. 1990 [14] & Germany & $\mathrm{C}$ & 202 & 24.3 & 25.7 \\
\hline She et al. 1984 [43] & China & $\mathrm{C}$ & 200 & 37.0 & 63.0 \\
\hline Skandalakis et al. 1976 [13] & USA & $\mathrm{C}$ & 204 & 48.5 & 51.5 \\
\hline Uen et al. $2006[20]$ & Taiwan & $\mathrm{C}$ & 120 & 85.0 & 15.0 \\
\hline Zhang and Cheng 2011 [44] & China & $\mathrm{C}$ & 80 & 90.0 & 10.0 \\
\hline
\end{tabular}

TABLE 6: Subgroup analysis for relationship of the Recurrent Laryngeal Nerve to the Tracheoesophageal Groove.

\begin{tabular}{|c|c|c|c|c|c|}
\hline & $\begin{array}{l}\text { Number of studies } \\
\text { (number of nerves) }\end{array}$ & $\begin{array}{l}\text { Inside TEG: } \\
\%(95 \% \mathrm{CI})\end{array}$ & $\begin{array}{c}\text { Outside TEG: } \\
\%(95 \% \mathrm{CI})\end{array}$ & $\begin{array}{c}I^{2}: \%(95 \% \\
\mathrm{CI})\end{array}$ & $\begin{array}{c}\text { Cochran's } Q, \\
p \text { value }\end{array}$ \\
\hline Overall & $23(5970)$ & $\begin{array}{c}63.7 \\
(55.3-77.7)\end{array}$ & $\begin{array}{c}36.3 \\
(28.3-44.7)\end{array}$ & $\begin{array}{c}97.4 \\
(96.8-97.9)\end{array}$ & $<0.001$ \\
\hline Cadaveric & 15 (1912) & $\begin{array}{c}65.8 \\
(50.7-79.5)\end{array}$ & $\begin{array}{c}34.2 \\
(20.5-49.3)\end{array}$ & $\begin{array}{c}97.7 \\
(97.1-98.2)\end{array}$ & $<0.001$ \\
\hline Intraoperative & $8(4058)$ & $\begin{array}{c}60.1 \\
(49.9-70.0)\end{array}$ & $\begin{array}{c}39.9 \\
(30.0-50.1)\end{array}$ & $\begin{array}{c}97.0 \\
(95.7-97.9)\end{array}$ & $<0.001$ \\
\hline Asia & 10 (1757) & $\begin{array}{c}75.9 \\
(60.2-88.9)\end{array}$ & $\begin{array}{c}24.1 \\
(11.1-39.8)\end{array}$ & $\begin{array}{c}97.8 \\
(97.0-98.4)\end{array}$ & $<0.001$ \\
\hline Europe & $9(3678)$ & $\begin{array}{c}50.9 \\
(38.0-63.7)\end{array}$ & $\begin{array}{c}49.1 \\
(36.3-62.0)\end{array}$ & $\begin{array}{c}97.7 \\
(96.8-98.3)\end{array}$ & $<0.001$ \\
\hline North America & $3(384)$ & $\begin{array}{c}57.5 \\
(45.4-69.1)\end{array}$ & $\begin{array}{c}42.5 \\
(30.9-54.6)\end{array}$ & $\begin{array}{c}78.8 \\
(32.3-93.3)\end{array}$ & 0.009 \\
\hline Right & $10(1597)$ & $\begin{array}{c}62.1 \\
(48.1-75.2)\end{array}$ & $\begin{array}{c}37.9 \\
(24.8-51.9)\end{array}$ & $\begin{array}{c}95.3 \\
(93.2-96.8)\end{array}$ & $<0.001$ \\
\hline Left & $10(1554)$ & $\begin{array}{c}68.0 \\
(56.4-78.6)\end{array}$ & $\begin{array}{c}32.0 \\
(21.4-43.6)\end{array}$ & $\begin{array}{c}93.4 \\
(21.4-43.6)\end{array}$ & $<0.001$ \\
\hline $\begin{array}{l}\text { Sensitivity ( } \geq 100 \\
\text { nerves) }\end{array}$ & $14(5334)$ & $\begin{array}{c}54.9 \\
(45.3-64.3)\end{array}$ & $\begin{array}{c}45.1 \\
(35.7-54.7)\end{array}$ & $\begin{array}{c}97.6 \\
(97.0-98.2)\end{array}$ & $<0.001$ \\
\hline
\end{tabular}


TABLE 7: Subgroup analysis for position of a Recurrent Laryngeal Nerve located outside the Tracheoesophageal Groove.

\begin{tabular}{|c|c|c|c|c|c|c|c|}
\hline & $\begin{array}{l}\text { Number of studies } \\
\text { (number of nerves) }\end{array}$ & $\begin{array}{l}\text { Anterior: } \\
\%(95 \% \text { CI })\end{array}$ & $\begin{array}{c}\text { Anterolateral: } \\
\%(95 \% \mathrm{CI})\end{array}$ & $\begin{array}{c}\text { Lateral: } \\
\%(95 \% \text { CI })\end{array}$ & $\begin{array}{l}\text { Posterior: } \\
\%(95 \% \text { CI })\end{array}$ & $\begin{array}{c}I^{2}: \%(95 \% \\
\mathrm{CI})\end{array}$ & $\begin{array}{c}\text { Cochran's } Q, \\
p \text { value }\end{array}$ \\
\hline Overall & $10(1268)$ & 45.7 (1.1-81.1) & $6.0(0-32.0)$ & $37.4(0-72.1)$ & $10.9(0-40.7)$ & $\begin{array}{c}99.4 \\
(99.2-99.5)\end{array}$ & $<0.001$ \\
\hline Cadaveric & $7(531)$ & $47.0(0-82.0)$ & $7.5(0-36.6)$ & $26.1(0-62.6)$ & $19.5(0-54.8)$ & $\begin{array}{c}98.8 \\
(98.5-99.1)\end{array}$ & $<0.001$ \\
\hline Intraoperative & $3(737)$ & $41.7(0-100)$ & $2.7(0-100)$ & $54.2(0-100)$ & $0.4(0-100)$ & $\begin{array}{c}99.5 \\
(99.3-99.6)\end{array}$ & $<0.001$ \\
\hline Europe & 7 (1098) & $23.0(0-61.6)$ & $3.3(0-28.6)$ & $59.8(6.1-93.9)$ & $13.9(0-49.3)$ & $\begin{array}{c}99.3 \\
(99.1-99.4)\end{array}$ & $<0.001$ \\
\hline North America & $3(170)$ & $85.6(46.5-100)$ & $10.4(0-42.1)$ & $0.6(0-16.5)$ & $3.3(0-26.2)$ & $\begin{array}{c}95.3 \\
(89.6-97.9)\end{array}$ & $<0.001$ \\
\hline Right & $5(515)$ & $38.0(0-100)$ & $3.2(0-47.2)$ & $50.7(0-100)$ & $8.1(0-60.7)$ & $\begin{array}{c}99.0 \\
(98.7-99.3)\end{array}$ & $<0.001$ \\
\hline Left & $5(433)$ & $27.1(0-76.5)$ & $6.3(0-44.4)$ & $56.7(0-100)$ & $9.9(0-52.1)$ & $\begin{array}{c}98.5 \\
(97.8-99.0)\end{array}$ & $<0.001$ \\
\hline Sensitivity (> 100) & $4(1051)$ & $35.7(0-100)$ & $0.8(0-100)$ & $42.7(0-100)$ & $20.8(0-100)$ & $\begin{array}{c}99.7 \\
(99.6-99.8)\end{array}$ & $<0.001$ \\
\hline
\end{tabular}

BL and TEG in nerve identification is valuable regardless of whether procedures are of primary or secondary nature and can provide valuable surgical information allowing for reduction of iatrogenic nerve injuries.

Additional research in this area is needed for a number of reasons. Future clinical trials need to be conducted to assess the intraoperative viability of the BL and TEG as landmarks for identifying the RLN, primarily through assessing the prevalence of iatrogenic RLN injury. Establishment of the $\mathrm{BL}$ and TEG as truly significant markers for at-risk neural structures requires further prospective studies of high power and sound methodology.

This meta-analysis was limited by several factors: in particular, the studies did not report the location of the RLN with respect to the TEG uniformly. This restricted the overall analysis to the distinction "inside or outside the TEG" rather than a more detailed assessment such as inside, anterior, anterolateral, posterolateral, and posterior. Two separate analyses could be completed on these variables, but they cannot be compared to each other. Moreover, the high heterogeneity among studies persisted despite substantial subgroup analysis, suggesting it could be attributed to intrinsic population variability in prevalence. Further limiting factors included the lack of any quality assessment and risk-of-bias tool for anatomical studies, and a lack of assessment of publication bias, as no statistical measure is currently available for anatomical prevalence meta-analysis. Throughout the study, the original authors were contacted when necessary and available in attempts to resolve discrepancies, provide clarification, and minimize bias.

\section{Conclusions}

The use of anatomical landmarks for identifying structures intraoperatively is valuable in many procedures, including those in the neck. The BL and TEG are both essential for performing complication-free thyroidectomies. The BL proved the more reliable of the two landmarks with $78.2 \%$ of RLNs coursing superficially to it. The TEG was slightly less consistent, with $68.1 \%$ of nerves found within the groove. The development of a uniform and consistent procedure, such as identifying the RLN in the TEG and tracing it upwards to the BL for confirmation, will help to preclude iatrogenic injuries and avoid complications. The confirmation of reliable landmarks on which to base those procedures is the first step in that process.

\section{Competing Interests}

The authors declare no conflict of interests.

\section{Acknowledgments}

This study was supported using the statutory funds of the Jagiellonian University Medical College. Krzysztof A. Tomaszewski was supported by the Foundation for Polish Science (FNP). We wish to thank Karolina Saganiak for the anatomical drawings used in this manuscript. The publication of this manuscript was supported by the Faculty of Medicine, Jagiellonian University Medical College KNOW (Leading National Research Centre 2012-2017) funds.

\section{References}

[1] A.-R. Ngo Nyeki, L.-R. Njock, J. Miloundja, J.-E. Evehe Vokwely, and G. Bengono, "Recurrent laryngeal nerve landmarks during thyroidectomy," European Annals of Otorhinolaryngology, Head and Neck Diseases, vol. 132, no. 5, pp. 265-269, 2015.

[2] S. Sasou, S.-I. Nakamura, and H. Kurihara, "Suspensory ligament of berry: its relationship to recurrent laryngeal nerve and anatomic examination of 24 autopsies," Head and Neck, vol. 20, no. 8 , pp. $695-698,1998$. 
[3] E. Asgharpour, E. Maranillo, J. Sañudo et al., "Recurrent laryngeal nerve landmarks revisited," Head and Neck, vol. 34, no. 9, pp. 1240-1246, 2012.

[4] P. Williams, R. Warwick, M. Dyson, and L. Bannister, Eds., Gray's Anatom, Churchill Livingstone, Edinburgh, Scotland, 1989.

[5] G. Gremillion, A. Fatakia, A. Dornelles, and R. G. Amedee, "Intraoperative recurrent laryngeal nerve monitoring in thyroid surgery: is it worth the cost?" Ochsner Journal, vol. 12, no. 4, pp. 363-366, 2012.

[6] G. Ardito, L. Revelli, L. D’Alatri, V. Lerro, M. L. Guidi, and F. Ardito, "Revisited anatomy of the recurrent laryngeal nerves," American Journal of Surgery, vol. 187, no. 2, pp. 249-253, 2004.

[7] D. Berlin and F. Lahey, "Dissections of the recurrent and superior laryngeal nerves," Surgery, Gynecology \& Obstetrics, vol. 49, pp. 102-104, 1929.

[8] B. Ö. Çakir, I. Ercan, B. Şam, and S. Turgut, "Reliable surgical landmarks for the identification of the recurrent laryngeal nerve," Otolaryngology-Head and Neck Surgery, vol. 135, no. 2, pp. 299-302, 2006.

[9] G. Freschi, C. Masi, M. P. Graziani et al., "Anatomic and surgical considerations regarding the recurrent laryngeal nerve in thyroidectomy," Minerva Chirurgica, vol. 49, no. 10, pp. 943947, 1994.

[10] P. S. Hunt, M. Poole, and T. S. Reeve, "A reappraisal of the surgical anatomy of the thyroid and parathyroid glands," British Journal of Surgery, vol. 55, no. 1, pp. 63-66, 1968.

[11] C. K. Leow and A. J. Webb, "The lateral thyroid ligament of berry," International Surgery, vol. 83, no. 1, pp. 75-78, 1998.

[12] P. V. Pradeep, B. Jayashree, and S. S. Harshita, "A closer look at laryngeal nerves during thyroid surgery: a descriptive study of 584 nerves," Anatomy Research International, vol. 2012, Article ID 490390, 6 pages, 2012.

[13] J. E. Skandalakis, C. Droulias, N. Harlaftis, S. Tzinas, S. W. Gray, and J. T. Akin Jr., "The recurrent laryngeal nerve," American Surgeon, vol. 42, no. 9, pp. 629-634, 1976.

[14] J. Menck, J. Gruber, and W. Lierse, "Anterior approach to the cervical vertebral column and the recurrent laryngeal nerve," Unfallchirurg, vol. 93, no. 8, pp. 384-386, 1990.

[15] X. Chen, L. Xie, and X. Guo, "The regional dissection and clinical application in pars cervicalis of recurrent laryngeal nerve," Sichuan Journal of Anatomy, vol. 10, no. 3, pp. 150-152, 2002.

[16] L. Chen, X. Lin, and M. Zheng, "The anatomical character and the clinical significance of the recurrent laryngeal nerve," Fujian Medical Journal, vol. 30, no. 1, pp. 6-8, 2008.

[17] D. Moher, A. Liberati, J. Tetzlaff, D. G. Altman, and PRISMA Group, "Preferred reporting items for systematic reviews and meta-analyses: the PRISMA statement," PLoS Medicine, vol. 6, no. 7, Article ID e1000097, 2009.

[18] J. Higgins and S. Green, Eds., Cochrane Handbook for Systematic Reviews of Interventions, The Cochrane Collaboration, London, UK, 2011.

[19] B. M. Henry, K. A. Tomaszewski, and J. A. Walocha, "Methods of evidence-based anatomy: a guide to conducting systematic reviews and meta-analysis of anatomical studies," Annals of Anatomy, vol. 205, pp. 16-21, 2016.

[20] Y.-H. Uen, T.-H. Chen, J.-F. Shyu et al., "Surgical anatomy of the recurrent laryngeal nerves and its clinical applications in Chinese adults," Surgery Today, vol. 36, no. 4, pp. 312-315, 2006.
[21] B. Yalçin and H. Ozan, "Detailed investigation of the relationship between the inferior laryngeal nerve including laryngeal branches and ligament of Berry," Journal of the American College of Surgeons, vol. 202, no. 2, pp. 291-296, 2006.

[22] J. W. Serpell, "New operative surgical concept of two fascial layers enveloping the recurrent laryngeal nerve," Annals of Surgical Oncology, vol. 17, no. 6, pp. 1628-1636, 2010.

[23] S. Chang, H.-H. Tang, C.-C. Wang et al., "A standard approach to expose the recurrent laryngeal nerve during endoscopic thyroidectomy," Journal of Laparoendoscopic and Advanced Surgical Techniques, vol. 22, no. 3, pp. 259-263, 2012.

[24] B. M. Henry, J. Vikse, M. J. Graves et al., "Extralaryngeal branching of the recurrent laryngeal nerve: a meta-analysis of 28,387 nerves," Langenbeck's Archives of Surgery, vol. 401, no. 7, pp. 913-923, 2016.

[25] A. Pisanu, G. Porceddu, M. Podda, A. Cois, and A. Uccheddu, "Systematic review with meta-analysis of studies comparing intraoperative neuromonitoring of recurrent laryngeal nerves versus visualization alone during thyroidectomy," Journal of Surgical Research, vol. 188, no. 1, pp. 152-161, 2014.

[26] D. Pironi, S. Pontone, M. Vendettuoli et al., "Prevention of complications during reoperative thyroid surgery," Clinica Terapeutica, vol. 165, no. 4, pp. e285-e290, 2014.

[27] D. Berlin, "The recurrent laryngeal nerves in total ablation of the normal thyroid gland," Surgery, Gynecology \& Obstetrics, vol. 60, 1935.

[28] J. B. Botelho, D. M. Vieira, D. M. De Carvalho, and M. B. P. Batista, "Anatomy surgical study of relations between the recurrent laryngeal nerves and the ligament of Berry," Revista do Colegio Brasileiro de Cirurgioes, vol. 39, no. 5, pp. 364-367, 2012.

[29] W. Kaisha, A. Wobenjo, and H. Saidi, "Topography of the recurrent laryngeal nerve in relation to the thyroid artery, Zuckerkandl tubercle, and Berry ligament in Kenyans," Clinical Anatomy, vol. 24, no. 7, pp. 853-857, 2011.

[30] H. Sunanda, S. Tilakeratne, and K. De Silva, "Surgical anatomy of the recurrent laryngeal nerve, a cross-sectional descriptive study," Galle Medical Journal, vol. 15, no. 1, pp. 14-16, 2010.

[31] J. S. Wade, "Vulnerability of the recurrent laryngeal nerves at thyroidectomy," British Journal of Surgery, vol. 43, pp. 164-180, 1955.

[32] A. R. Al-Salihi and A. W. Dabbagh, "Anatomy of the recurrent laryngeal nerve in normal Iraqis," Acta Anatomica, vol. 135, no. 3, pp. 245-247, 1989.

[33] Á. Altorjay, Z. Tihanyi, F. Luka et al., "Place and value of the Recurrent Laryngeal Nerve (RLN) palpatory method in preventing RLN palsy during thyroid surgery," Head and Neck, vol. 31, no. 4, pp. 538-547, 2009.

[34] W. G. Armstrong and J. W. Hinton, "Multiple divisions of the recurrent laryngeal nerve. An anatomic study," AMA Archives of Surgery, vol. 62, pp. 532-539, 1951.

[35] R. E. M. Bowden, "The surgical anatomy of the recurrent laryngeal nerve," British Journal of Surgery, vol. 43, no. 178, pp. 153-163, 1955.

[36] A. N. Hisham and M. R. Lukman, "Recurrent laryngeal nerve in thyroid surgery: a critical appraisal," ANZ Journal of Surgery, vol. 72, no. 12, pp. 887-889, 2002.

[37] J. Iqbal and M. Zubair, "Anatomical considerations regarding recurrent laryngeal nerve in relation with thyroid surgery," Journal of the College of Physicians and Surgeons Pakistan, vol. 8, no. 6, pp. 276-277, 1998. 
[38] Y. Jiang, P. Dong, X. Li, J. Zhu, G. Wang, and J. Zhang, “The significance of anastomosing the recurrent laryngeal nerve in the thyroidectomy," Lin Chuang er Bi Yan Hou Tou Jing Wai Ke Za Zhi, vol. 22, no. 12, pp. 544-550, 2008.

[39] Y. Jing, J. Zheng, J. Chen, and W. Shen, "Applied Anatomy of recurrent laryngeal nerve," Clinical Anatomy, vol. 12, pp. 427428, 2007.

[40] J. Lang, S. Nachbaur, and K. Fischer, "Laryngeal nerves, branches in the interior of the larynx," Gegenbaurs morphologisches Jahrbuch, vol. 132, no. 5, pp. 723-736, 1986.

[41] J. Lang, K. Fischer, S. Nachbaur, and H. W. Meuer, "Course and branches of the recurrent laryngeal nerve, inferior thyroid artery and inferior laryngeal artery," Gegenbaurs Morphologisches Jahrbuch, vol. 132, no. 5, pp. 617-643, 1986.

[42] Z. Lu, J. Zou, Y. Wan, H. Cao, and W. Xu, "Relationship between the recurrent laryngeal nerve and the inferior thyroid artery and its branches: an applied anatomical study," Chinese Archives of Otolaryngology-Head and Neck Surgery, vol. 19, pp. 548-551, 2012.

[43] B. She, P. Sheng, and G. Zhang, "Anatomic Study of the recurrent laryngeal nerve," Academic Journal of Guangzhou Medical College, vol. 12, pp. 31-37, 1984.

[44] H. Zhang and M. Cheng, "Anatomy of the Cervical recurrent laryngeal nerve," Shandong Medical Journal, vol. 51, pp. 110-111, 2011. 

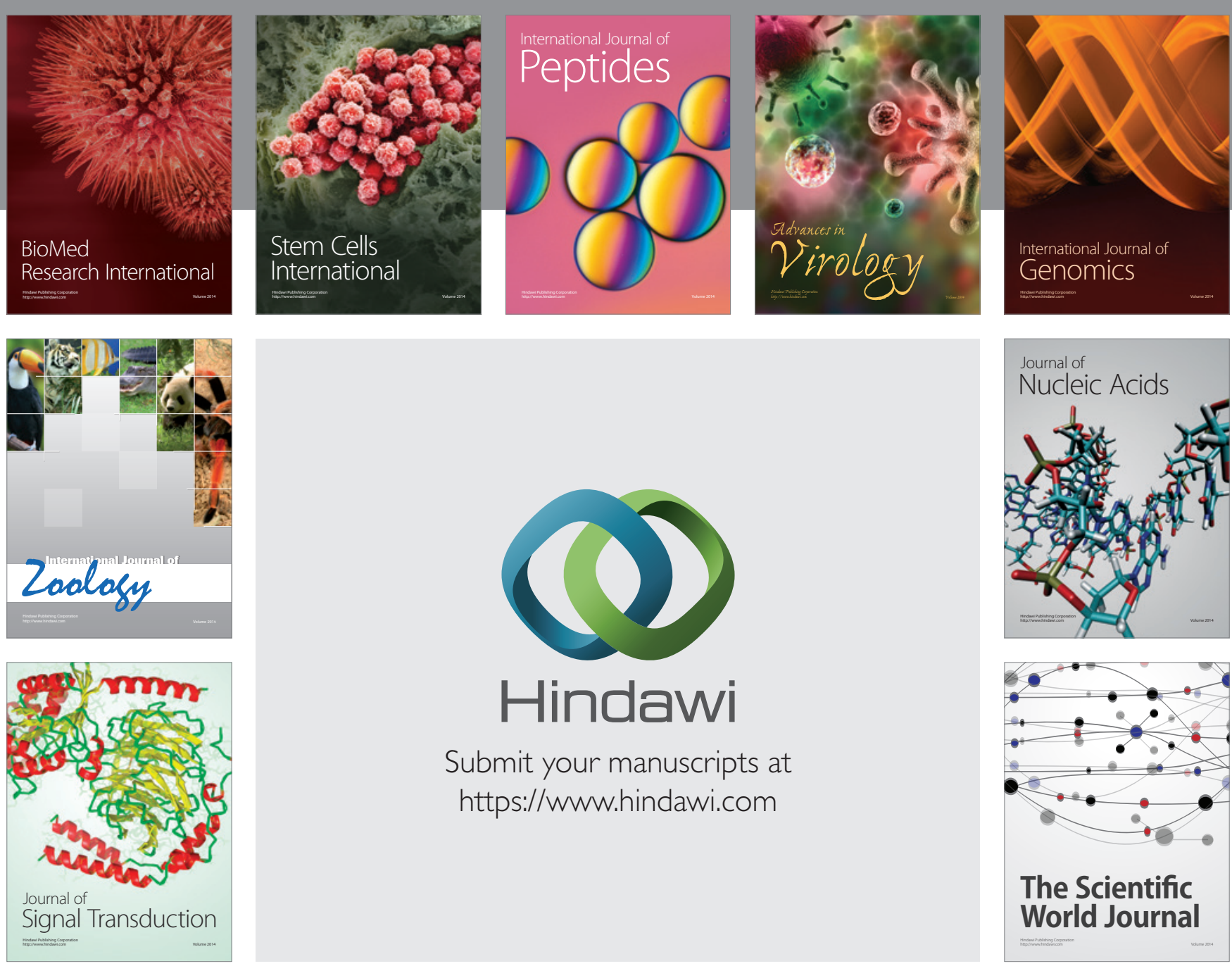

Submit your manuscripts at

https://www.hindawi.com
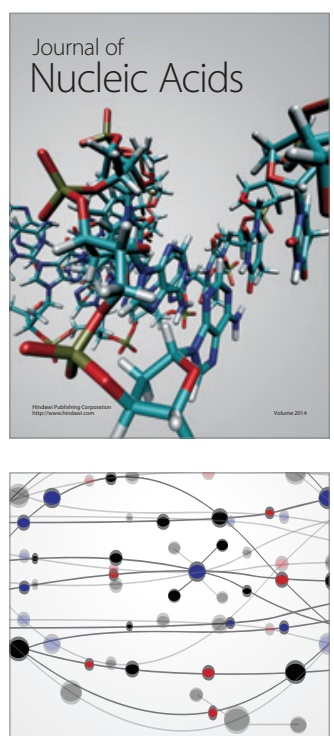

The Scientific World Journal
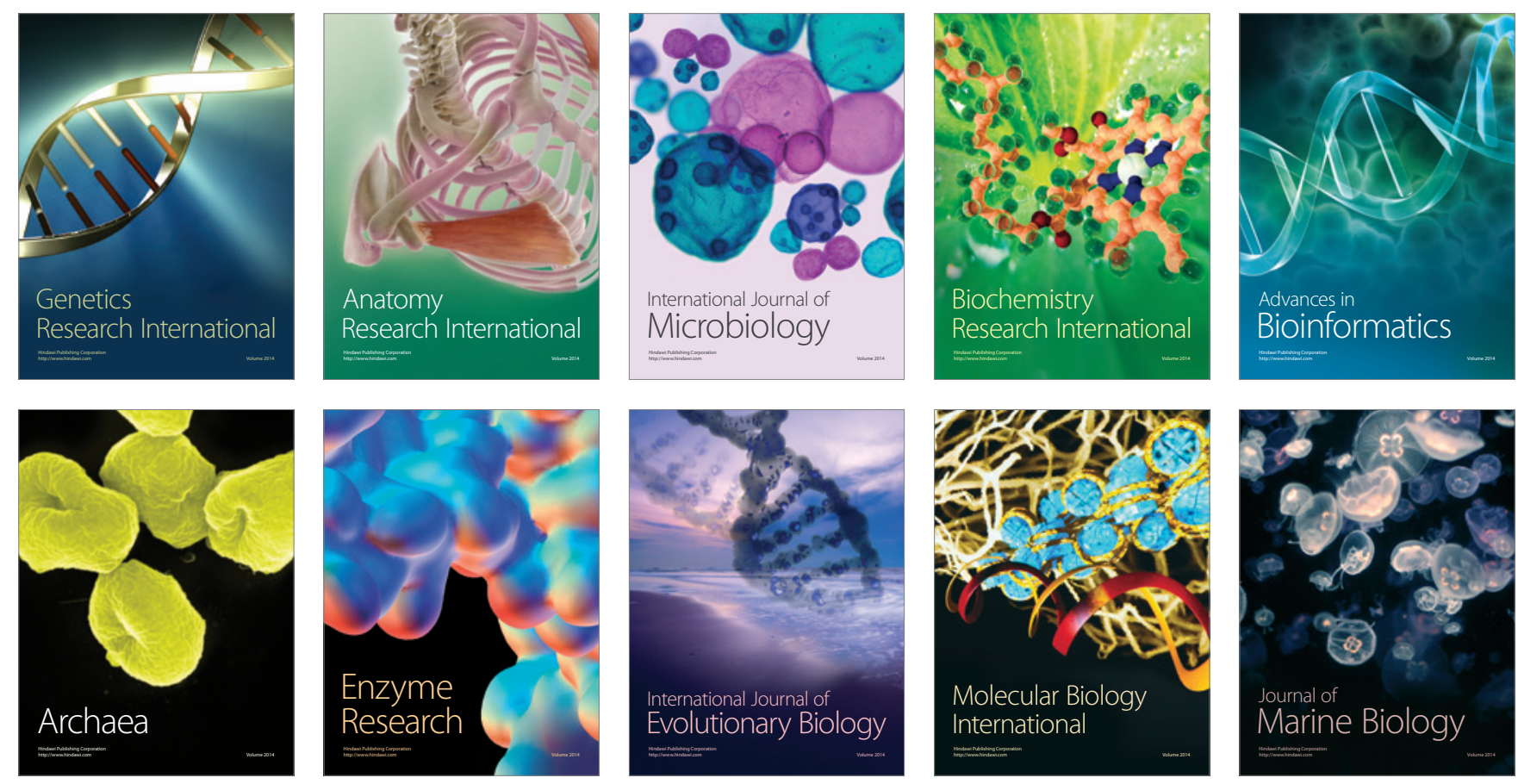